\title{
Online Radio Pathologic Correlation
}

\section{David Quintero}

MD Specialist Interventional Radiology eHealth Master Degree, Universidad Oberta Cataluña España, Universidad de Antioquia, Colombia

*Corresponding author: David Quintero, MD Specialist Interventional Radiology eHealth Master Degree, Universidad Oberta Cataluña España, Universidad de Antioquia, Colombia, E-mail: davidqv84@gmail.com

Received date: July 05, 2018; Accepted date: September 19, 2018; Published date: September 28, 2018

Copyright: @2018 Quintero D. This is an open-access article distributed under the terms of the Creative Commons Attribution License, which permits unrestricted use, distribution, and reproduction in any medium, provided the original author and source are credited.

\begin{abstract}
We present a 2 years the experience using a web portal to review the results of histological analysis and pathologies of biopsies taken by the interventionist radiology service of Medellin Clinic and North Clinics in the city of Medellín, of patients that cannot access the review physically like outpatient, therefore with the privacy standards can send the histopathological result via internet and the results are reviewed by one of the professionals who send recommendations for each patient adhering to the privacy and confidentiality standards of the Clinical Record favoring thus the ICT (information and communication technologies). MESH Telemedicine Radiology Continuity of Patient Care Histology-www.mediart.co.
\end{abstract}

Keywords: Biopsies; Interventionist radiology; Telemedicine; Histopathological review

\section{Introduction}

Colombia is a country with limitation of basic and more complex health services, especially those specialized in diagnostic imaging and interventional procedures performed with medical imaging guidance [1]. The department of Antioquia has an adverse topography that makes transportation to the city of Medellín complicated [2].

Appointments with medical specialists [3,4] have multiple delays, the medical professionals are located in the capital city and patients from rural areas must travel long distances in order to access specialized services for biopsies. After the diagnostic procedure is performed, the histopathological review at the control visit is fundamental for a clinical radiopathological correlation [5], which is consistent with the clinical evolution, the imaging appearance and the result pathological, for which the specialist interventionist must review all the pathologies of the patients involved.

A control visit represents costs and delays for the patient since many of them due to their socio-economic conditions, do not have the possibility for returning to the city easily. For these patients, a Web page with Web Interest in Health (WIS) certification [6] has been developed where they can register and send their results for the radiopathological correlation. These patients understand and accept this type of review in order to avoid losing this benefit and send their diagnostic images for review by the specialist interventional radiologist.

The results of the implementation of this program are presented. More than 150 pathologies have been reviewed and all the patients have been adequately addressed with the improvement in the quality of the provision of biopsy taking services, empowering the patient, taking responsibility for their care and empowering it with the use of internet technology in their favor in a country with serious limitations of attention by medical specialists.

\section{Justification}

Due to geographic or economical limitations or disability, patients cannot easily attend control visits after interventional procedures for pathology review. Thus they have requested a different form of accessing the interventional radiology service for radiopathological correlation.

This service is free and is included in the "should be" of the provision of interventional radiology, so that before information was provided through personal mail or even by voice or messages on the personal mobil of the interventional doctor. With the increase in demand and with the perception of doing it in a more professional way, on the personal page a message box application was created in which patients register with their personal email, they accept terms and conditions of treatment under de General Data Protection Regulation (GDPR) of their data and asynchronously they send the information for the complementary evaluation to the biopsy taking, which is the final analysis in which the clinical presentation, the radiological image and the pathological analysis are integrated with the intention of providing a personalized service.

\section{Materials and Methodology}

For the last six years, in the service of interventional radiology. The day of the biopsy, the possibilities for reviewing the pathology result are explained; either face to face consultation during a new appointment or by means of an asynchronous telemedicine consultation through a certified application on a web page in accord with the Colombian regulations for telemedicine. For the Tele-Revision or Tele-Review, only patients who want this form that best suits their needs.

The information of the page and the application is extended and the informed consent is signed for this type of assessment, in addition to the acceptance of terms that make the digital form when accessing the page using verification in a personal email.

Subsequently, the portal sends the verification codes and messages through a mailbox, so that the doctor can answer the patients' 
questions and order behaviors (Figures $1,2 \mathrm{a}$ and $2 \mathrm{~b}$ ) such as repetition in the case of an inconclusive biopsy, follow-up in case of benignant or interconsultation by interdisciplinary group in case of malignant result A simple easy to understand language is used and all patients doubts are solved and clarified.

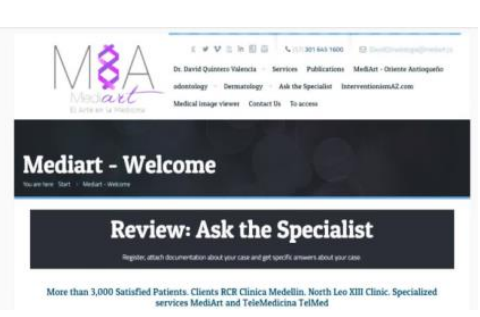

Figure 1: Image of the web portal.

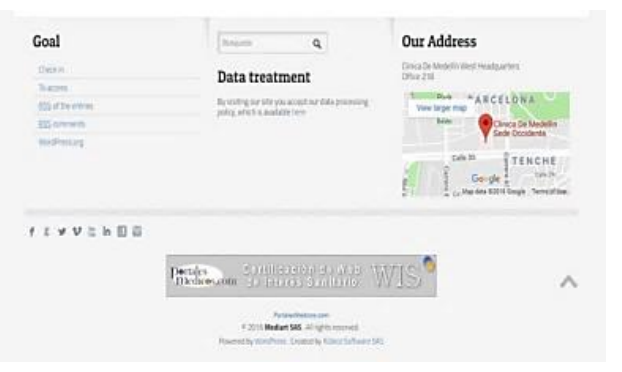

Figure 2a: Presentation of web portal.

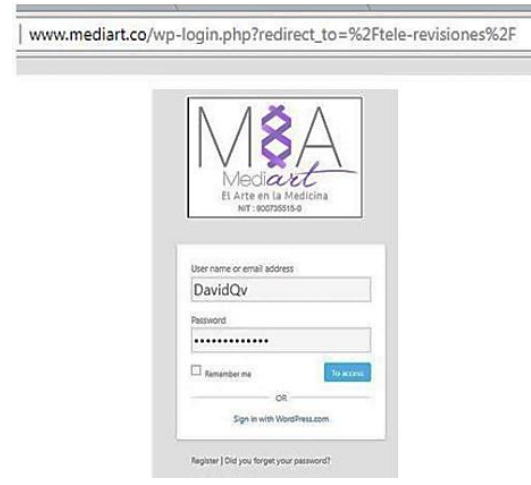

Figure 2b: Mail like interface to answer the consultation.

\section{Results}

It has been performed more than 3,000 procedures and these have been performed asynchronously radiopathological correlation through the portal of 190 patients (Figure 3), with a percentage of $80 \%$ a single interaction and $20 \%$ for more than an interaction in relation to orders of examinations and follow-up of recommendations.

There have been offered and performed 5 interventional treatments [7] of benign lesions that in the country in general are not performed due to low availability of the percutaneous sclerosis service of benign thyroid cysts.

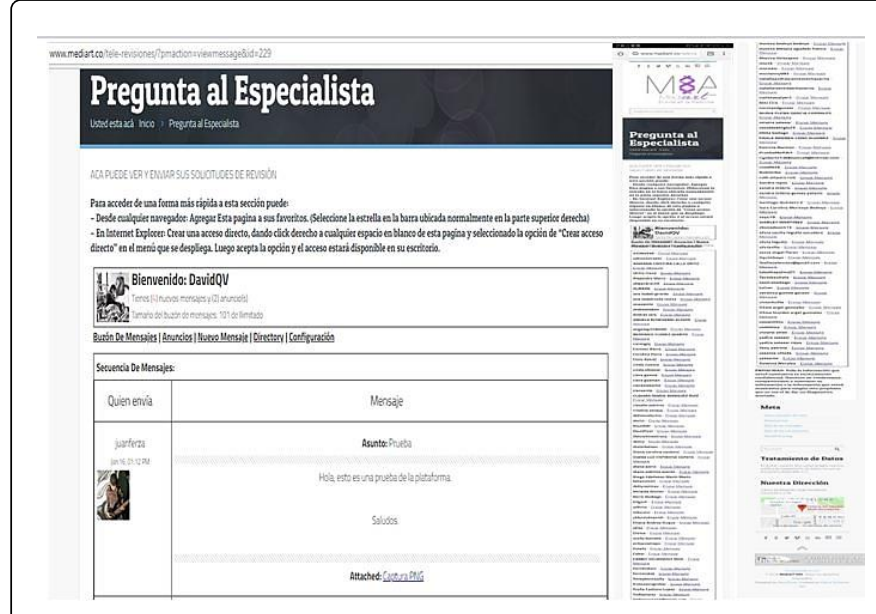

Figure 3: Directory 190 ptes-present by this way to conservation of privacy (In Spanish).

\section{Discussion: eHealth and TeleMedicine}

It is important to clarify the terms where eHealth is any type of approach related to health from the digital universe, while Tele Medicine refers to a more personalized interaction dedicated to providing a service [8].

Advances in medical technology are imposed in all aspects, as we have reviewed in the references, eHealth and TeleMedicine are not new, but with the advance in the digitalization of data, networks, communications technologies and the information every time they are taking more importance in the electronic everyday life and in this way the technological services will invariably migrate to these virtual digital scenarios overcoming the geographical and temporal barriers.

Regarding the evidence, it is a very robust issue to define the type of eHealth interaction, if it is through specific programs and platforms, if it is only used to solve doubts or if telemetry devices are used to make the interaction more physical, if cameras, camera type, type of light, data network, service availability, synchronous or asynchronous, if they are eHealth activities for the general public or involve specialized consultation including remote intervention with robots and technological developments that facilitate the TelePresence, of service at home or in reference center [9] of this medical literature is full of data and it becomes a huge task to group it, something that epidemiologists know very well with all their statistical machinery, in this way the epidemiological evidence [10] that supports the use of technology, should be assessed for each particular case, from the review of the evidence we see how the benefits of Telemedicine are shown in chronic diseases such as cardiovascular diseases, diabetes, dermatology, radiology including mobile teleradiology [11] for second opinion, ophthalmology rehabilitation and psychiatry, with limitations to demonstrate impacts on survival, for example, not so clear in other aspects such as Tele ICU (Intensive care unit) and neonatal care, even suggesting an increase in costs and unnecessary interventions in the latter population [12].

Promising is the scenario of current human realities and virtualities where every time information and data represent a high percentage of the lives of people in general and of patients specifically, we also see unintended effects such as the cost overrun in patient involved in 
Page 3 of 4

telemedicine projects, in addition to a higher hospitalization rate, such as in asthma, or even the technical difficulties of the devices involved, with performance in the rehabilitation area that have shown benefit (Table 1) [13].

\begin{tabular}{|c|c|c|}
\hline Author year & Intervention & Conclusion \\
\hline Walter 2012 & Mobil unity of stroke & Rapid Thrombolisys [14] \\
\hline Bergrath 2012 & TeleConsultation (TeleMetry and Video) & Retardation in both [15] \\
\hline Audebert 2009 & Video consultation Neurologist TeleRx equals a Rx & Strong recomendation [16] \\
\hline Meyer 2008 & TeleMedicine vs Phone & Better with TeleMedicine [17] \\
\hline Takao 2004 & TeleMedicine versión Twitter Staff & Better results on time [18] \\
\hline Schwam 2009 & HighQuaVTC and Teleradiology FDA & Equals presence radiology staff [19] \\
\hline Ilana 2014 & TeleRx vs Neuro Stroke & Correlation to avoid RTPA [20] \\
\hline Bart 2014 & TeleRx TeleNrxTeleNeuroStrok & Good correlation [21] \\
\hline Demaershalk & App Movil ResMD & Good Correlation TeleRx y Neuro [22] \\
\hline Johnston 2009 & TeleRx Nuero or Radio specialist & Good correlation in great findings [23] \\
\hline Kim 2011 & PACS DICOM vs TeleJPEG2000 compression 5y10/1 & Well ASPECTS scale in movil [24] \\
\hline
\end{tabular}

Table 1: Resume of some papers.

As a particular conclusion from the radiological aspect, the technology prevailed and standards were achieved in both modalities radiology and teleradiology, giving equivalence of face-to-face and distance reading by Telemedicine.

Other advantages to explore for the future are the reliability of electronic devices advantages to prevent the spread of infectious diseases for example.

The comfort and privacy of the patient to be attended to remotely conservation of private subjects. Many patients will prefer a nondisplaced teleconsultation with privacy and eye contact through a camera or remote wereables than having to share their vulnerability with the entire healthcare team.

Another advantage to explore can be the security of the information. Without losses and with globalized access. There is still a long way to investigate and define [25].

But undoubtedly the internet is here to stay and with this paradigm shift, health will evolve hand in hand. This is a small approach to a world of possibilities for patient medical interaction in the context of future telemedicine.

\section{Barriers}

Difficulties of some patients have been documented for the correct completion of the web form, related with digital alphabetization, and as all the forgetting of the passwords, in general are the biggest difficulties, besides the analysis of each case can take up to 24 hours to fix, with the consequent anxiety that presents the patient pending its radiopathological correlation.

\section{Opportunities}

Patients are becoming aware of the importance of their own management of the disease and with technological support are continuously updated through the pages of medical content and social networks that are directed from the web portal.

\section{Conclusion}

Patients are increasingly migrating to technological services of all kinds, in Colombia specifically the presence of approximately 14 million cell phones [26] favors the interaction of the financial system and currently the health service to schedule appointments, schedule surgeries and procedures, from the knowledge of the authors, this type of Tele-Revisiones in spanish or TeleReview service provided through the portal is unique in its type and is part of the effort of telemedicine implementation of the University of Antioquia with its master degree project in agreement with the University Oberta of Catalonia.

\section{References}

1. European Society of Radiology (2018) Summary of the proceedings of the International Forum 2017: "Position of interventional radiology within radiology" 9: 189-197.

2. Agencia EFE (2014) un negocio que busca mejorar el servicio de salud en Colombia,Telemedicina.

3. Saulacic N, Zix J, lizuka T (2009) Complication rates and associated factors in alveolar distraction osteogenesis: a comprehensive review. Int J Oral Maxillofac Surg 38: 210-217.

4. López-valcárcel DBG (2008) Oferta y necesidad de especialistas médicos en España

5. Llanos SN, Rivas PF, Es C (2014) PAAF guiada por ecografia. Resultados y correlación radiopatológica. Serie de 267 pacientes. EPOS.

6. González Murillo (2018) WIS Web de Interes Sanitario.

7. Baek JH, Lee JH, Valcavi R, Pacella CM, Rhim H (2011) Thermal ablation for benign thyroid nodules: Radiofrequency and laser. Korean J Radiol 12: 525-540.

8. Giovanni W, Barbosa J, Sareth J, Gómez A (2015) Advances in e-health and telemedicine: Strategy to bring health service users. Acta Odontológica Colomb Enero Junio 5: 101-115. 
9. Hersh WR, Hickam DH, Severance SM, Dana TL, Krages KP (2006) Diagnosis, access and outcomes: Update of a systematic review of telemedicine services. J Telemed Telecare 12: S3-31.

10. Totten AM, Womack DM, Eden KB, McDonagh MS, Griffin JC (2016) Telehealth: Mapping the evidence for patient outcomes from systematic reviews.

11. Society ESR (2018) ESR paper on the proper use of mobile devices in radiology 9: 247-251.

12. Gerd F, Antoine R, J FA, Marco I, Sasha S (2015) Interactive telemedicine: Effects on professional practice and health care outcomes.

13. Ekeland AG, Bowes A, Flottorp S (2010) Effectiveness of telemedicine: A systematic review of reviews. Int J Med Inform 79: 736-771

14. Walter S, Kostopoulos P, Haass A, Keller I, Lesmeister M, et al. (2012) Diagnosis and treatment of patients with stroke in a mobile stroke unit versus in hospital: A randomised controlled trial. Lancet Neurol 11: 397-404.

15. Bergrath S, Reich A, Rossaint R, Rörtgen D, Gerber J, et al. (2012) Feasibility of prehospital teleconsultation in acute stroke - a pilot study in clinical routine. PLoS One 7: e36796.

16. Audebert HJ, Schwamm L (2009) Telestroke: Scientific results. Cerebrovasc Dis. 27: 15-20.

17. Meyer (2009) NIH Public Access 34: 518-520.

18. Takao H, Murayama Y, Ishibashi T, Karagiozov KL, Abe T (2012) A new support system using a mobile device (smartphone) for diagnostic image display and treatment of stroke. Stroke 43: 236-239.
19. Schwamm LH, Holloway RG, Amarenco P, Audebert HJ, Bakas T, et al. (2009) A review of the evidence for the use of telemedicine within stroke systems of care: A scientific statement from the American heart association/American stroke association. Stroke 40: 2616-2634.

20. Ilana (2014) NIH Public Access. Sci Transl Med 6: 1-16.

21. Bart (2013) NIH Public Access 70: 646-656.

22. Demaerschalk BM, Vargas JE, Channer DD, Noble BN, Kiernan TEJ, et al. (2012) Smartphone teleradiology application is successfully incorporated into a telestroke network environment. Stroke 43: 3098-3101.

23. Johnston KC, Worrall BB (203) Teleradiology Assessment of Computerized Tomographs Online Reliability Study (TRACTORS) for acute stroke evaluation. Telemed J E-Health 9: 227-233.

24. Kim DK, Kim EY, Yang KH, Lee CK, Yoo SK (2011) A mobile teleradiology imaging system with JPEG2000 for an emergency care. J Digit Imaging 24: 7090-7018.

25. Currell R, Urquhart C, Wainwright P, Lewis R (2000) Telemedicine versus face to face patient care: effects on professional practice and health care outcomes. Cochrane Database Syst Rev CD002098.

26. Radio RCN (2016) Tan solo el 51\% de las personas en Colombia tienen celulares inteligentes. 